\title{
Validation of UV Spectrophotometric and HPLC Methods for Quantitative determination of chlorpyrifos
}

\author{
O. A. Zalat, M. A. Elsayed, M. S. Fayed, M. K. Abd EI Megid \\ Department of Chemical Engineering, Military Technical College, Kobry Elkobbah, Cairo, Egypt \\ E-mail address: zalat44@yahoo.com
}

\begin{abstract}
A specific and sensitive HPLC and UV spectrophotometric methodwere developed for determination and analysis of chlorpyrifos. Chromatographic separation was achieved on a $150 \mathrm{~mm} \mathrm{x}$ $10 \mathrm{~mm}$ I.D. reversed phase column Zorbax SB C-18. usingdeionizedwater: acetonitrile in the ratio of $10: 90 \mathrm{v} / \mathrm{v}$ respectively as mobile phase. The effluent was monitored at 290 and $230 \mathrm{~nm}$. Two sharp peaks were obtained for the solvent and chlorpyrifos at 2.7 and 3.45 min respectively. UV spectrophotometric method was performed at $290 \mathrm{~nm}$ using Isopropanol as the solvent. Linear range was $0.025-3500 \mathrm{ppm}\left(\mathrm{r}^{2}=0.9986 \pm 0.0009\right)$ for HPLC method and 2.229 to $200 \mathrm{ppm}\left(\mathrm{r}^{2}=0.9988\right)$ for UV spectrophotometric method. Validation guidelines and statistical analysis showed that both the methods were precise, accurate, sensitive, and can be used for the routine quality control of chlorpyrifos in waste discharges
\end{abstract}

Keywords: chlorpyrifos; HPLC; UV-spectrophotometric; liner range

\section{INTRODUCTION}

Chlorpyrifos[O,O-diethyl-O-3,5,6-trichloro-2-pyridylphosphorothioate] is an organophosphoruspesticide (OPP), which is a broadly active insecticide effective by ingestion and contact. The metabolites of chlorpyrifos being chlorpyrifos oxon, 3,5,6-trichloro-2pyridinol and diethyl phosphorothioic acid and/or diethyl phosphoric acid [1,2]. Chlorpyrifos is stable in air (nonvolatile) and it is not sensitive to ultra violet radiation. It is stable to neutral and weakly acidic solution, but it is hydrolysed by strong bases. The rate of chlorpyrifos hydrolysis increases with both $\mathrm{pH}$ and temperature [3]. Chlorpyrifos acts by phosphorylating acetylcholinesteraseboth at the synapse of neurons and in the plasma. The inactivation of the acetylcholinesterasecauses an accumulation of acetylcholine (ACh) which is normally hydrolysed by the enzyme, paralysing the synaptic site.

The manifestations of organophosphate poisoning are associated with the increase in concentration of $\mathrm{ACh}$ at the neuronesynapse [4]. Reduction in acetylcholinesterase activity to $10 \pm 20 \%$ of normal activity in man results usually in death [5]. Different chromatographic methods for the determination of chlorpyrifos in food and environmental samples [6-7]. For example, limits of detection (LOD) between 0.05 and $0.5 \mathrm{ng} / \mathrm{ml}$ were reached using thin layer chromatography (TLC) [8]; also high performance liquid chromatography (HPLC) with LOD 
of $16 \mathrm{ng} / 1$ for the analysis of chlorpyrifos in water [9]. In addition, gas chromatography (GC) coupled to nitrogen/phosphorous (NPD) [10-11], atomic emission (AED) [13], electron capture (ECD) [13] or flame photometric detectors (FPD) [14], have also been applied for the determination of chlorpyrifos.

The aim of this paper is to develop and validate HPLC method using a suitable conditions and UV spectrophotometric method for the determination of chlorpyrifos.

\section{MATERIALS AND METHODS}

Analytically pure chlorpyrifos, (assigned purity $>97 \%$ purity) was purchased from sigma Aldrich. Chloroform, Acetonitrile Water analytical grade -HPLC was purchased also from Sigma Aldrich.

\section{1. Instrumentation and analytical conditions}

Analytically pure chlorpyrifos (purity $>97 \%$ purity) were obtained from Sigma aldrich. HPLC grade chloroform, HPLC water, HPLC aceyonitril was obtained from Sigma aldrich. Isopropanol for standard solution prepartion for UV-Visible.

\section{2. Instrumentation and analytical conditions}

HPLC analyses were performed using the Agilent 1100 system equipped with an auto injector and ultraviolet detector (Agilent, Palo Alto, USA). A reversed-phase column (Eclipse XDB-C18; size: $250 \mathrm{~mm} \times 4.6 \mathrm{~mm}$ (i.d); particle size $5 \mu \mathrm{m}$ ) from Agilent Company was used for separation and maintained at $40{ }^{\circ} \mathrm{C}$.

The mobile phase was a mixture of acetonitrile /water/ glacial acetic (90/10/0.1, v/v/v) with a flow rate of $1.0 \mathrm{~mL} / \mathrm{min}$.the detection was at $290,230 \mathrm{~nm}$ when the injection volume was $1 \mu \mathrm{L}$.

The UV spectrophotometric method was performed using Shimadzue UV-Vis double beam spectrophotometer model 1700.UV-Vis double beam spectrophotometer is controlled by its control panel or using PC by UV probe personal software package. UV probe is modular approach to data collection, analysis, and reporting provides a rare simplicity and power.the samples wrer prepared using Isopropanol.

\section{3. Preparation of standard solutions}

For HPLC method, $3000 \mathrm{ppm}$ of chlorpyrifos was prepared by dissolving $3 \mathrm{mg}$ each in $100 \mathrm{ml}$ chloroform. Working standard solutions of chlorpyrifos $(1-30 \mu \mathrm{g} / \mathrm{mL})$ were prepared by transferring 0.1 to $3 \mathrm{ml}$ of chlorpyrifos stock solution to serially arranged $10 \mathrm{ml}$ standard flasks and diluting to volume using chloroform. For the UV spectrophotometric method, stock solution of $500 \mathrm{ppm}$ of chlorpyrifos was prepared in isopropanol.

The working standard solutions were prepared by dilution of the stock solution with isopropanol to get a concentration range $1-500 \mathrm{ppm}$ The absorbance was measured at $290 \mathrm{~nm}$ using isopropanol as blank.

\section{4. Linearity and range}

For the HPLC method, stock solution of chlorpyrifos was suitably diluted with chloroform to get concentrations in the linear range of 1-300 ppm. the peak area and retention times were recorded. 
The calibration curve for chlorpyrifos was constructed by plotting the ratio of the peak area of chlorpyrifos to against concentration and linearity was evaluated by linear regression equation. The slope, intercept and correlation coefficient valueswere recorded.

For the UV Spectrophotometric method, calibration graph was prepared with 2.229 to $200 \mathrm{ppm}$ of chlorpyrifos and absorbance was recorded at $290 \mathrm{~nm}$. Each experiment was performed in five replicates.

\section{5. Accuracy}

Accuracy is a measure of how closely the result of an experiment agrees with the expected result. The difference between the obtained result and the expected result is usually divided by the expected result and reported as a percent relative error. This was calculated by injecting standard solution of chlorpyrifos five times then recodring the accurcy of the methode.

\section{6. Precision}

The precision of the method was studied by repeatability (within-day) and intermediate precision (inter-day). The intra-day precision studies were carried out by estimating the response six times on the same day using standard concentration (80 ppm) for HPLC method and $100 \mathrm{ppm}$ for UV spectrophotometric method) of chlorpyrifos and inter-day precision studies were done by repeating the above procedure on three different days. The results of precision studies were expressed as \% RSD.

\section{7. LOD and LOQ}

Sensitivity of HPLC and UV methods were determined from limit of detection (LOD) and limit of quantitation (LOQ). The LOD and LOQ were calculated from the calibration curve using the following equations:

$\mathrm{LOD}=3.3 \times \sigma / \mathrm{S}$

$\mathrm{LOQ}=10 \times \sigma / \mathrm{S}$

where,

$\sigma=$ standard deviation of y intercept of regression line

$\mathrm{S}=$ slope of the calibration curve

\section{RESULTS AND DISCUSSION}

\section{1. HPLC Method}

The current study describes a HPLC method for the determination of chlorpyrifos. The retention times of chloroform and chlorpyrifos was 2.479 and $3.790 \mathrm{~min}$, respectively. Figure 1 shows the chromatogram of chlorpyrifos. 


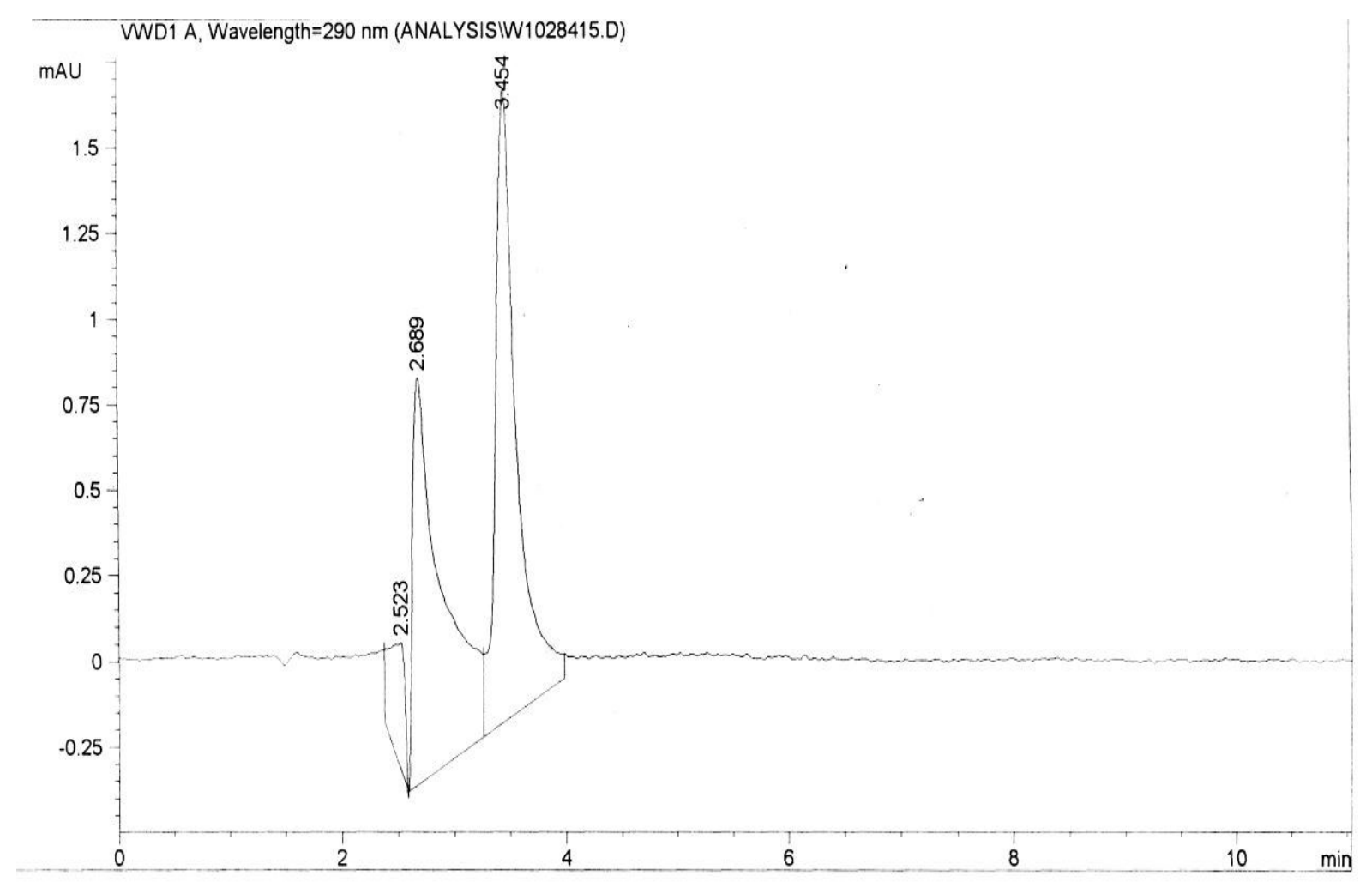

Figure 1. Chromatogram of chlornvrifos.

The developed method was validated in terms of linearity and range, accuracy, intra-day and inter-day precision, LOD and LOQ. The standard calibration curve showed in Fig. 2 was linear over the concentration range 0.05 to $3000 \mathrm{ppm}$ with a correlation coefficient $\left(\mathrm{r}^{2}\right)$ 0.9976. LOD and LOQ were found to be $0.05 \mathrm{ppm}$ and $0.5 \mathrm{ppm}$ respectively, indicating the sensitivity of the method. Experiments demonstrated satisfactory accuracy with small relative standard deviations 1.325 (RSD \%). The developed HPLC method was precise since the \% RSD values were $<2$ for both repeatability and intermediate precision studies. RSD of repeatability (intra-day) and intermediate precision (inter-day) ranged from 0.782 to 0.6085 and .9123 to 1.435 respectively. Chromatographic conditions were carefully optimized to get satisfactory resolution between analyte solvent used.

The final decision on mobile phase composition and flow rate was made on the basis of peak shape (peak area, asymmetry, tailing factor), baseline drift, time required for analysis, and cost of solvents. The optimized mobile phase was was a mixture of acetonitrile /water/ glacial acetic $(90 / 10 / 0.1, \mathrm{v} / \mathrm{v} / \mathrm{v})$ with a flow rate of $1.0 \mathrm{~mL} / \mathrm{min}$. the detection was made at 290 and $230 \mathrm{~nm}$ by making prlinimary expremient on the chlorpyrifos with usung mobile phase compostion as solvent on UV-Visible spectrophotomtreic showed that there was two peaks at 290 and 230 by applying the two wavlenths on the HPLC method the using of wave lenghth 230 shoed good response with it affected on the LOD to be $0.025 \mathrm{ppm}$. The proposed methods were also found to be precise and accurate, as depicted by the statistical data of analysis. 


\section{2. UV-Vis Spectrophotometric method}

The solutions were scanned in the wavelength range of $200-1100 \mathrm{~nm}$ after making suitable dilutions from the stock solutions. Chlorpyrifos showed absorption maxima at 290 $\mathrm{nm}$. chlorpyrifos in isopropanol as solvent showed linear relationship in the concentration range of 2.229 to $200 \mathrm{ppm}$ with a correlation coefficient $\left(\mathrm{r}^{2}\right)$ 0.9988. LOD and LOQ were found to be $2.2296 .754 \mathrm{ppm}$ respectively. The \% RSD values for intra-day and inter-day precision varied from 0.0531 to 0.0833 and 0.0912 to 0.1485 respectively. spectrophotometric method allowed rapid quantification of chlorpyrifos. Isopropanol was chosen as the solvent because of good solubility, cost and stability.

The spectral characteristics were also good in this solvent. Chlorpyrifos showed absorption maxima at $290 \mathrm{~nm}$ which was selected as the detection wavelength since it showed better linearity and sensitivity at this wavelength. Low values of \% RSD signify the precision of the method.

\section{CONCLUSIONS}

The validated HPLC and UV-Vis methods were found to be accurate, precise and reliable. UV spectrophotometric method was simpler however HPLC method was more sensitive and the same may be used as an alternative method when advanced instruments like HPLC are not available for routine quantification purpose. Both the methods can be employed for the routine quality control of chlorpyrifos in discharges.

\section{References}

[1] Sultatos L. G., S. D. Murphy, Fund. Appl. Toxicol. 3 (1983) 16-21.

[2] Sultatos L. G., M. Shao, S. D. Murphy, Toxicol. Appl. Phramacol. 73 (1984) 60-68.

[3] The National Registration Authority (NRA), Review of Chlorpyrifos, Septmber 2000, Volume 1.

[4] A. Goldstein, L. Aronow, S. M. Kalman. Principles of Drug Action: The Basis of Pharmacology, Wiley, New York, 1974.

[5] D. Grob, J. C. Harvey, J. Clin. Invest. 37 (1958) 350.

[6] US Food and Drug Administration, Pesticide Analytical Manual, Vol. I, FDA, Rockville, MD, 1979.

[7] P. Lopez-Roldan, M. J. Lopez de Alda, D. Barcelo, Anal. Bioanal. Chem. 378 (2004) 599.

[8] A. Pasha, Y. N. Vijayashankar, N. G. K. Karanth, J. AOAC Int. 79 (1996) 1009.

[9] A. Di Corcia, M. Marchetti, Anal. Chem. 63 (1991) 580.

[10] S. Magdic, A. Boyd-Boland, K. Jinno, J. B. Pawliszyn, J. Chromatogr. A 736 (1996) 219.

[11] P. L. Wylie, K. Uchiyama, J. AOAC Int. 79 (1996) 571. 
[12] B. F. Scott, J. Struger, H. Tse, J. Environ. Anal. Chem. 61 (1995) 129.

[13] N. K. Wilson, J. C. Chuang, C. Lyu, J. Expo. Anal. Environ. Epidemiol. 11 (2001) 449.

[14] D. E. Glotfelty, M. S. Majewski, J. N. Seiber, Environ. Sci. Technol. 24 (1990) 353.

(Received 29 October 2013; accepted 03 November 2013) 